\title{
Analytical performance of the selective, automatic multianalyser Olympus AU 5031
}

\author{
C. Luley $\nmid$, H. G. Struss and W. Prellwitz \\ Abteilung für Klinische Chemie und Laboratoriumsmedizin, Universitätsklinik der \\ Johannes-Gutenberg-Universität, Mainz, FR Germany
}

The analytical performance of the selective, automatic multianalyser Olympus AU 5031 was evaluated over four months and assessed for practicability for another eight months. The evaluation followed the ECCLS guidelines. Twenty routine parameters were measured. In addition, sodium and potassium were determined on an attached flame photometric unit. Both the agreement between the eights photometers per unit and the temperature behaviour in the cuvettes was satisfactory. The imprecisions were very good. The within-run imprecision was below $1.5 \%$ for the majority of the parameters. The imprecision between days was below $5 \%$, with the exception of creatine phosphokinase $(7 \cdot 4 \%)$. Glutamate dehydrogenase gave an imprecision of between $4.0 \%$ and $15.9 \%$, which, however, is more likely due to the low activities measured rather than the fault of analyser. The recovery of the assigned values in 12 control sera was between $95 \%$ and $105 \%$ for 14 tests. Three of the remaining eight tests yielded recoveries with deviations between $10 \%$ and $18 \%$ (alanine aminotransferase, aspartate aminotransferase and bilirubin). No drift effects were observed and neither a sample carry-over nor a reagent carry-over were detected. Most tests were linear over a very wide range. Only a few tests (mainly lipase and glutamate dehydrogenase) required measurement repetitions with diluted samples. The correlation with routine instruments and tests was close. However, corrections were necessary for 14 of the 22 tests. This was not due to the performance of the analyser but, rather, to the different methodologies of compared tests, or different working temperatures on the comparison instruments, or a lack of accuracy for some of the $A U$ tests.

\section{Introduction}

The Olympus AU is an analyser for medium and large laboratories. This paper reports on the performance of the AU 5031. The evaluation lasted six months and the instrument has been in routine use for a further eight months. Although the authors accept that only a multicentre evaluation, as suggested by ECCLS guidelines [1], allows a truly representative assessment for an analyser, multicentre evaluations of analysers of this size require considerable time. The evaluation data are reported here because there is a growing interest in the performance characteristics of the Olympus 5000.

The protocol of this evaluation followed the ECCLS guidelines; changes were made only if they seemed appropriate to the specific features of the AU analyser.

† To whom correspondence should be addressed. Present address: Zentrallabor der Universitätsklinik, Hugstetter Strasse 55, 7800 Freiburg, FR Germany.
Recently, two evaluations of this analyser have been published [1 and 2]. They, too, followed the ECCLS guidelines but some aspects reported here were not studied or were approached differently. Therefore, the present data and that in the previous reports may serve as a preliminary multicentre evaluation.

\section{General description of the AU 5000 analyser}

The AU 5000 Analyser is constructed according to a modular concept. Any analyser consists of up to eight units. Each unit is basically a complete analyser and is equipped with either four, eight or 12 reagent lines. The specifications of such a unit are given in table 1. By combining several units the performance of the resulting analyser can be tailored to the requirements of the user in respect to sample throughput, number of tests or both. By choosing the maximum number of 12 reagent lines, the user gains a higher number of available tests at the cost of sample throughput. Possible combinations of available test numbers and throughput capacities are displayed in table 2. However, once a certain configuration is installed it must remain permanent.

In cases of malfunction of a unit, it can be exchanged in less than an hour. Consequently, any AU analyser which contains more than one unit, can, to a certain degree, supply its own back-up system. However, some parts of the analyser have a common function, and, in the event of failure, will cause the analyser to stop. The most important of these is the sample rack transport system and the data-processing unit.

The AU configuration which was evaluated, an AU 5031, consists of three units with eight reagent lines per unit. It processes 150 samples per hour and with an additional (optional) flame photometer carries out 26 tests per sample. Twenty-four cuvettes are assigned to each test and complete one cycle of the cuvette wheel in $8 \mathrm{~min}$, and $24 \mathrm{~s}$. If a test is not required for a given sample, the cuvette passes empty and is washed. Consequently, the processing speed remains constant regardless of the number of tests required for a given sample.

Most of the reagents kits for the AU 5000 were from the Merck Company in Darmstadt, FR Germany. However, there are other suppliers who offer tests which are tailored to this analyser. In addition, since this system is entirely open, many commercial tests can be adapted to the analyser. 
Table 1. Instrument specifications for the AU 5031.

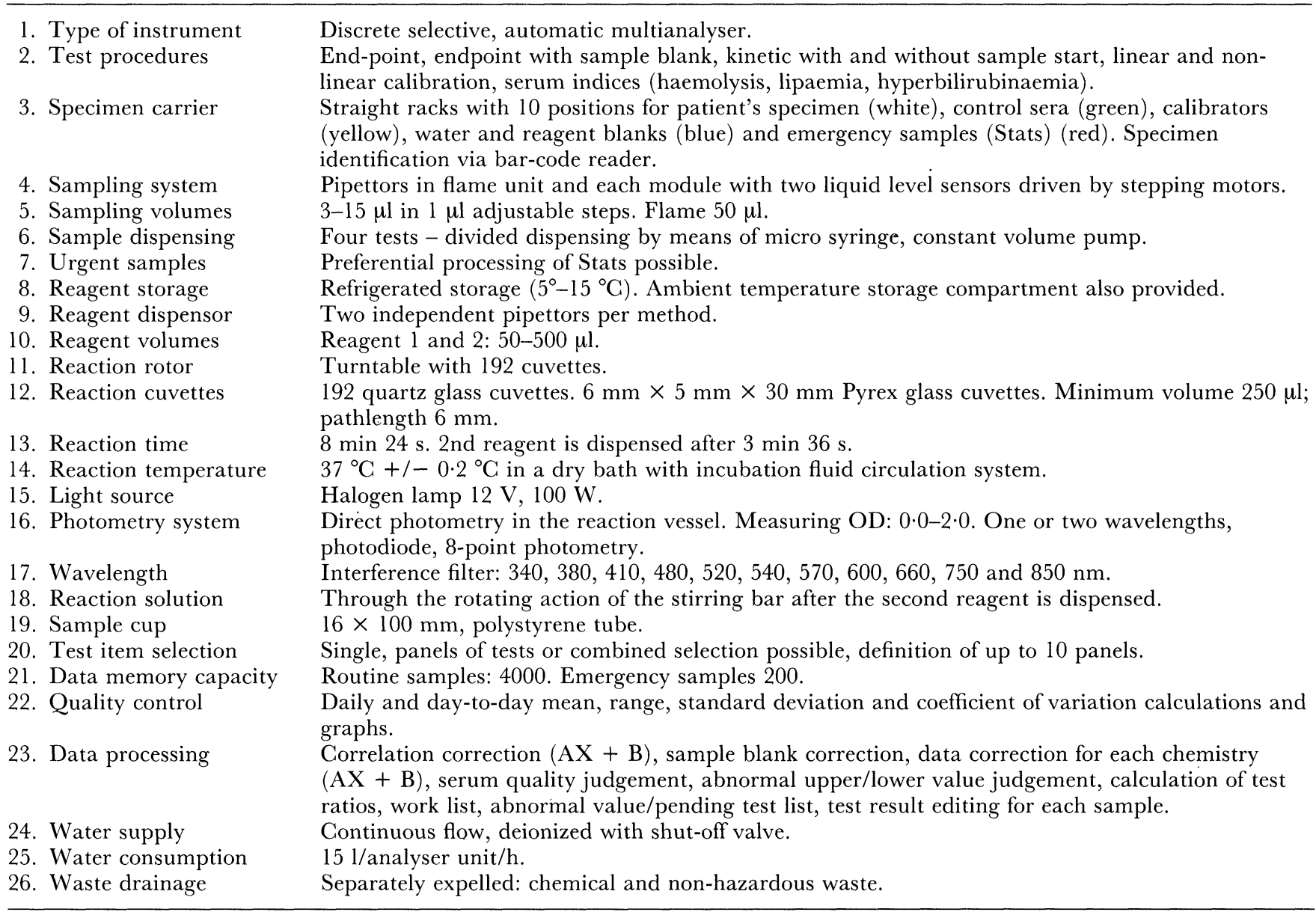

\section{Methods}

\section{Agreement between photometer and temperature behaviour in cuvettes}

Two hardware conditions were investigated: the linearity in all eight photometers in a unit and the temperature behaviour in a cuvette after addition of cooled $\left(8^{\circ} \mathrm{C}\right)$ reagent 1 .

For the linearity experiment, two solutions were prepared with NADH and para-nitrophenol, respectively, which covered in seven dilution steps the extinction range between 0.5 and 3.0 for each solution. The extinctions of each solution were measured in triplicate and were plotted in eight parallel extinction curves for visual inspection of linearity and parallelity.

The temperature in the cuvette was measured with a micro temperature sensor in a cuvette to which $10 \mu \mathrm{l}$ of sample and, $12 \mathrm{~s}$ later, $500 \mu \mathrm{l}$ of reagent 1 was added. In order to ensure that cooled reagent $1\left(8^{\circ} \mathrm{C}\right)$ reached the cuvette, the reagent was dispensed repeatedly immediately before the experiment. The rationale of this experiment was to check whether the temperature in the cuvette reached $37^{\circ} \mathrm{C}$ before reading by photometer 1,168 s later.

Table 2. Analyser configurations and throughput.

\begin{tabular}{|c|c|c|c|c|c|c|}
\hline Number of units & 1 & 2 & 3 & 4 & 6 & 8 \\
\hline Number of reagent lines per unit & 12 & $12 / 8$ & $8 / 4$ & $8 / 4$ & 4 & 4 \\
\hline Available tests per analyser & 24 & $24 / 16$ & $24 / 12$ & $32 / 16$ & 24 & 32 \\
\hline Sample processing capacity (per h) & 50 & $100 / 150$ & $150 / 300$ & $150 / 380$ & 300 & 300 \\
\hline
\end{tabular}


Table 3. Reagents used during the evaluation.

\begin{tabular}{|c|c|c|}
\hline Analyte & Method & Manufacturer \\
\hline \multicolumn{3}{|l|}{ 1. Enzymes } \\
\hline \multirow[t]{2}{*}{ Alkaline } & 'Opt. stand. method' $\dagger$ & Merck \\
\hline & & 14000 \\
\hline \multirow[t]{2}{*}{ Alanine aminotransferase } & Opt. UV-test; modified & $\begin{array}{l}\text { Merck } \\
\text { IFCC method }\end{array}$ \\
\hline & & $\begin{array}{l}14344 \\
140 \text { method }\end{array}$ \\
\hline \multirow[t]{3}{*}{ Amylase } & Substrate: 2-Cl-PNP- & Merck \\
\hline & & $\beta, \mathrm{D}$-maltoheptaosid \\
\hline & & $14159 / 158$ \\
\hline \multirow[t]{3}{*}{ Aspartate aminotransferase } & Opt. UV-test; modified & Merck \\
\hline & & IFCG method \\
\hline & & 14346 \\
\hline \multirow[t]{2}{*}{ Creatine phosphokinase } & 'Opt. stand. method' & Merck \\
\hline & & $14109 / 111$ \\
\hline \multirow{2}{*}{$\gamma$-glutamyl transferase (new) } & ‘Szasz’ & Merck \\
\hline & & $14056 / 057$ \\
\hline \multirow[t]{2}{*}{ Glutamate dehydrogenase } & 'Opt. stand. method' & Boehringer \\
\hline & & 124320 \\
\hline \multirow[t]{2}{*}{ Lactate dehydrogenase } & Opt. stand. method' & Merck \\
\hline & & 3399 \\
\hline \multirow[t]{3}{*}{ Lipase } & Turbidimetry substrate & Boehringer \\
\hline & & Triolein \\
\hline & & 262358 \\
\hline \multicolumn{3}{|l|}{ 2. Flame photometry } \\
\hline \multirow[t]{2}{*}{ Sodium } & With flame photometer & Merck \\
\hline & & Lithium as internal standard \\
\hline \multirow[t]{2}{*}{ Potassium } & With flame photometer & Merck \\
\hline & & Lithium as internal standard \\
\hline \multicolumn{3}{|l|}{ 3. Substrates } \\
\hline \multirow[t]{2}{*}{ Blood urea nitrogen } & Urease/glutamate dehydrogenase & Merck \\
\hline & & $\begin{array}{l}14135 / 137 / 161 \\
\text { Merck }\end{array}$ \\
\hline Bilirubin & $\begin{array}{l}\text { 2,5-Dichlorophenyl-diazonium salt } \\
\text { (DPD) }\end{array}$ & $\begin{array}{l}\text { Merck } \\
14162 / 163\end{array}$ \\
\hline \multirow[t]{2}{*}{ Calcium } & ortho-cresol-phthalein-complexon & Merck \\
\hline & & 19724 \\
\hline \multirow[t]{2}{*}{ Cholesterol } & Cholesterol oxidase/peroxidase & Merck \\
\hline & (CHOD-PAP) & $14138 / 139 / 140 / 141$ \\
\hline \multirow[t]{2}{*}{ Creatinine } & Modified Jaffé without deproteiniza- & Merck \\
\hline & tion & $19726 / 727$ \\
\hline \multirow[t]{2}{*}{ Glucose } & Glucose dehydrogenase without & Merck \\
\hline & deproteinization & $14051 / 055$ \\
\hline \multirow[t]{2}{*}{ Phosphate } & Molybdate reaction & Merck \\
\hline & & 19723 \\
\hline \multirow[t]{2}{*}{ Iron } & Ferrozin method & Merck \\
\hline & & 19725 \\
\hline Magnesium & Xylidylblue & Merck \\
\hline & & 19736 \\
\hline Total protein & Biuret reaction & Merck \\
\hline & & 3327 \\
\hline Triglycerides & Enzymatic UV-test & Merck \\
\hline & & $14151 / 148$ \\
\hline Uric acid & Uricase/peroxidase & Merck \\
\hline & & $14126 / 27 / 28$ \\
\hline
\end{tabular}

† Optimized standard method according the Deutsche Gesellschaft für Klinische Chemie.

NN: not yet in the catalogue.

\section{Reagents and comparison instruments}

The reagents used in this evaluation are listed in table 3. The comparison instrument and the reagents used in the comparison instrument are given in table 4 . While some comparison procedures were virtully identical (in particular most enzymes), the following were different in either chemistry or test principle: amylase, BUN, bilirubin, calcium, magnesium and uric acid.. In addition, there were differences in measurement temperatures: while the AU 5031 works at $37^{\circ} \mathrm{C}$ some of the comparison procedures operated at either $25^{\circ} \mathrm{C}$ (amylase, lipase, lactate dehydrogenase, $\mathrm{BUN}$, cholesterol, creatinine, 
Table 4. Analytical instruments and tests used for method comparison.

\begin{tabular}{|c|c|c|c|}
\hline Analyte & Instrument & Method & Reagents \\
\hline \multicolumn{4}{|l|}{ 1. Enzymes } \\
\hline Alkaline phosphatase & ERIS $^{1}$ & 'Opt. stand. method' & $\begin{array}{l}\text { Merck } \\
19711\end{array}$ \\
\hline Alanine aminotransferase & ERIS $^{1}$ & $\begin{array}{l}\text { Opt. UV-test; modified IFGC } \\
\text { method }\end{array}$ & $\begin{array}{l}\text { Merck } \\
19709\end{array}$ \\
\hline Amylase & COBAS BIO $^{2}$ & Substrate: Maltotetraose & $\begin{array}{l}\text { Gödecke } \\
847899\end{array}$ \\
\hline Aspartate aminotransferase & ERIS $^{1}$ & $\begin{array}{l}\text { Opt. UV-test; modified IFCG } \\
\text { method }\end{array}$ & $\begin{array}{l}\text { Merck } \\
19708\end{array}$ \\
\hline Creatine phosphokinase & ERIS $^{1}$ & 'Opt. stand. method' & $\begin{array}{l}\text { Merck } \\
19715\end{array}$ \\
\hline$\gamma$-glutamyl transferase (new) & ERIS $^{1}$ & 'Szasz' & $\begin{array}{l}\text { Merck } \\
19710\end{array}$ \\
\hline Glutamate dehydrogenase & ERIS $^{1}$ & 'Opt. stand. method' & $\begin{array}{l}\text { Merck } \\
19734\end{array}$ \\
\hline Lactate dehydrogenase & COBAS BIO ${ }^{2}$ & 'Opt. stand. method' & $\begin{array}{l}\text { Merck } \\
3399\end{array}$ \\
\hline Lipase & HITACHI $705^{3}$ & UV-test; substrate: Triolein & $\begin{array}{l}\text { Boehringer } \\
262358\end{array}$ \\
\hline \multicolumn{4}{|l|}{ 2. Flame photometry } \\
\hline Sodium & $\mathrm{FL} 7^{4}$ & $\begin{array}{l}\text { With flame photometer } \\
\text { lithium as internal standard }\end{array}$ & \\
\hline Potassium & $\mathrm{FL} 7^{4}$ & $\begin{array}{l}\text { With flame photometer } \\
\text { lithium as internal standard }\end{array}$ & \\
\hline \multicolumn{4}{|l|}{ 3. Substrates } \\
\hline Blood urea nitrogen & $\mathrm{SMA}^{5}$ & Diacetyl monoxime method & $\begin{array}{l}\text { Technicon } \\
\text { T40-0001 }\end{array}$ \\
\hline Bilirubin & COBAS $\mathrm{BIO}^{6}$ & Jendrassik Grof reaction & $\begin{array}{l}\text { Hoffmann la } \\
\text { Roche } \\
0710032\end{array}$ \\
\hline Calcium & $\mathrm{FL} 7^{7}$ & Atom absorption & \\
\hline Cholesterol & COBAS $\mathrm{BIO}^{2}$ & $\begin{array}{l}\text { Cholesterol oxidase/peroxidase } \\
\text { (CHOD-PAP) }\end{array}$ & $\begin{array}{l}\text { Boehringer } \\
692905\end{array}$ \\
\hline Creatinine & $\mathrm{SMA}^{5}$ & Jaffé & $\begin{array}{l}\text { Technicon } \\
\text { T40-0004 }\end{array}$ \\
\hline Phosphate & $\mathrm{SMA}^{5}$ & Molybdate reaction & $\begin{array}{l}\text { Technicon } \\
\text { T40-0012 }\end{array}$ \\
\hline Iron & COBAS BIO 6 & Ferrozin method & $\begin{array}{l}\text { Hoffman la } \\
\text { Roche } \\
0710598\end{array}$ \\
\hline Magnesium & FL7 & Atom absorption & \\
\hline Total protein & COBAS $\mathrm{BIO}^{6}$ & Biuret & $\begin{array}{l}\text { Hoffman la } \\
\text { Roche } \\
0710083\end{array}$ \\
\hline Triglycerides & COBAS BIO ${ }^{6}$ & Enzymatic UV-test & $\begin{array}{l}\text { Merck } \\
14360\end{array}$ \\
\hline Uric acid & $\mathrm{SMA}^{5}$ & Sodium tungstate method & $\begin{array}{l}\text { Technicon } \\
\text { T40-0014-00 }\end{array}$ \\
\hline
\end{tabular}

${ }^{1}$ ERIS: Eppendorf Gerätebau Netheler + Hinz GmbH, Hamburg, FR Germany.

${ }^{2}$ COBAS BIO: Hoffmann la Roche \& Co. AG, Basel, Switzerland.

${ }^{3}$ HITACHI: Boehringer, Mannheim, FR Germany.

${ }^{4}$ FL 7: Zeiss GmbH, Oberkochem, FR Germany.

${ }^{5}$ SMA: Technicon GmbH, Bad Vilbel, FR Germany.

${ }^{6}$ COBAS BIO: Hoffmann la Roche \& Co. AG, Basel, Switzerland.

${ }^{7}$ FL 7: Zeiss GmbH, Oberkochem, FR Germany. 
phosphate, uric acid) or $30^{\circ} \mathrm{C}$ (bilirubin). All enzyme activities which were measured on the AU 5031 at $37^{\circ} \mathrm{C}$ were converted to corresponding activities at $25^{\circ} \mathrm{C}$.

\section{Imprecision}

The within-run imprecision was determined from 20 measurements of three commercial control sera. Care was taken to include a control serum containing normal analyte levels (Monitrol I). The series were repeated three times and the medians of the three $\mathrm{CV}$ values were taken as the final results.

The same sera were used for the determination of between-day imprecision, which was determined over 21 days (18 working days).

Predetermined factors were used for the measurement of enzyme activities. Substrate and electrolyte concentrations were calibrated every day with the same calibrator ('Calibrator for automated systems', Boehringer Mannheim GmbH, Catalogue No. 759 350). The control sera used in this experiment are listed in table 5.

\section{Drift}

Drift effects were studied using three commercial and control sera covering different levels of the analytes measured. The sera were dissolved in the morning and split into nine aliquots which were sealed and kept at $4{ }^{\circ} \mathrm{C}$ until use. Measurements of aliquots were carried out every $60 \mathrm{~min}$ for $8 \mathrm{~h}$. For determination of alkaline phosphase and bilirubin the sera were freshly reconstituted every $2 \mathrm{~h}$.

\section{Range limits}

Linear ranges were investigated for all tests either by diluting very high concentrations or activities, respectively, of the analyte, or by spiking human serum with the pure analyte. The measured concentrations were plotted against dilutions and the resulting graphs were inspected visually for linearity.

\section{Carry-over}

Carry-over effects are limited due to the construction principle that each cuvette is used for one test only. However, carry-over might occur as sample carry-over due to insufficient cuvette washing (specimen-related carry-over), through inadequate cleaning of the mixer blades (specimen-independent carry-over).

\section{Specimen-related carry-over}

Sample carry-over was tested by determining the activity of alkaline phosphatase during two complete cuvette wheel cycles $(N=48$ samples $)$. All samples were taken from a serum pool with a low activity of $63 \mathrm{U} / 1$, except sample numbers 6 to 10 and 16 to 20 which contained the very high activity of $5200 \mathrm{U} / \mathrm{l}$. Thus, during the second cuvette wheel cycle (sample numbers 25 to 48 ) samples containing the low activity were measured in cuvettes which were used for the determination of a very high activity of the analyte in the previous cuvette wheel cycle. If the cuvettes are washed, residue of the sample with high alkaline phosphatase activity should cause elevated results in cuvette numbers 6 to 10 and 16 to 20, respectively.

\section{Specimen-independent carry-over}

In order to investigate the potential reagent carry-over by mixer blades, the combination of lipase and triglyceride determinations was chosen. The first reagent line in a single unit was used for lipase assay and the fifth reagent line for the triglyceride test. Since samples were processed in groups of four, the first of the four mixer blades stirred first the lipase reaction mixture in cuvette 1 and subsequently (after the mixer blade washing procedure) the reaction mixture for the triglyceride determination in cuvette 5 .

This should lead to falsely high measurements of triglyceride if reaction solution was transferred from cuvette (lipase assay) to cuvette 5 (triglyceride assay). If the triglyceride determination only was required, the prewashed mixer blade just stirred the triglyceride reaction solutions in cuvette numbers $5+8 N(0<N<24)$ in this unit. Thus, a potential carry-over from cuvettes $1+8 N$ to

Table 5. Control sera used for the AU 5031 evaluation

\begin{tabular}{lll}
\hline & & \\
Control serum & Lot No. & Manufacturer Control \\
\hline $\mathrm{N}+\mathrm{D}$ Moni-trol I $\dagger$ & 208 & AHS/Deutschland GmbH, \\
$\mathrm{M}+\mathrm{D}$ Moni-trol II $\dagger$ & 108 & Bereich Merz + Dade \\
Validate N $\dagger$ & $4 \times 023$ & Gödecke AG, \\
Validate A & $4 \times 625$ & Freiburg, FRG \\
Seronorm & 174 & E. Merck AG, \\
Pathonorm L & 20 & Darmstadt, FRG \\
Pathonorm H & 21 & \\
Precipath E & 152147 & Boehringer \\
Precipath U & 151464 & Mannheim GmbH, \\
Precinorm U & 154290 & FRG \\
Kontrollogen-L & $623125 \mathrm{~B}$ & Behringwerke \\
Kontrollogen-LP & $623211 \mathrm{H}$ & AG, Marburg/Lahn \\
& & FRG \\
\hline
\end{tabular}

$\dagger$ Used for determination of imprecision; all control sera were used in the recovery study. 

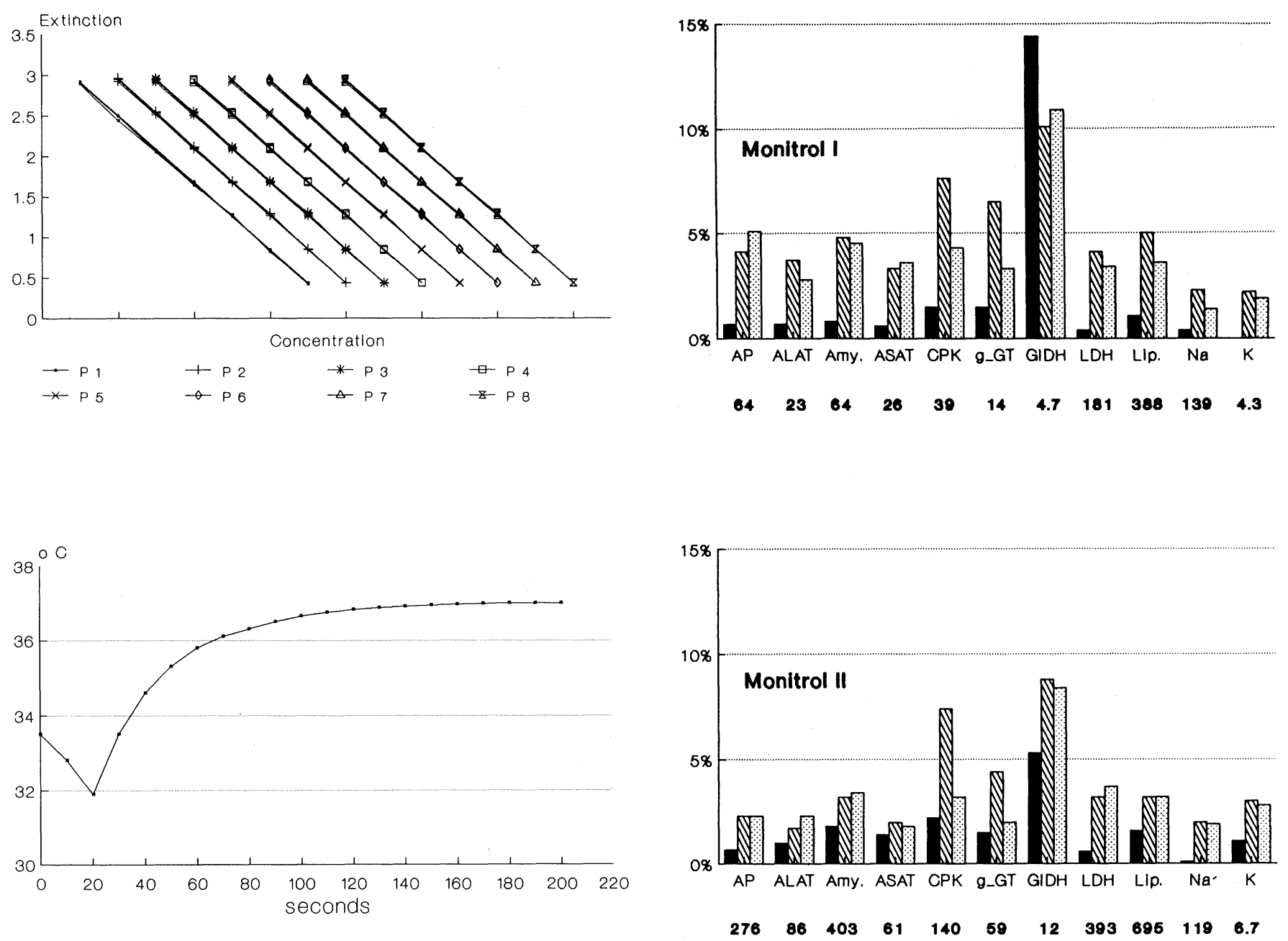

Figure 1. Linearity and reproducibility of all eight photometers in a unit as measured by dilutions of paranitrophenol in triplicate (top). The temperature course in a cuvette upon addition of precooled $\left(8^{\circ} \mathrm{C}\right)$ is displayed below.

cuvettes $5+8 N$ could be investigated by measuring triglycerides with and without determining lipase activity. This was carried out by determining the triglyceride levels in quadruplicate in 10 human serum samples, covering triglyceride levels between 0.4 and $4 \cdot 3$ $\mathrm{mmol} / \mathrm{l}$, with and without simultaneous lipase determinations. The triglyceride values of both groups (with and without lipase measurement) were compared by means of the Wilcoxon test.

\section{Assessment of accuracy}

Recovery of assigned values in quality-control sera

Twelve commercial sera had been selected for the determination of the recovery of assigned values in control sera (see table 5).

\section{Comparison with other analytical routine procedures}

One hundred fresh human sera from daily routine samples were determined in the AU 5031 analyser and in the comparison instrument. Care was taken to ensure simultaneous measurement of both instruments and to include pathological analyte levels.

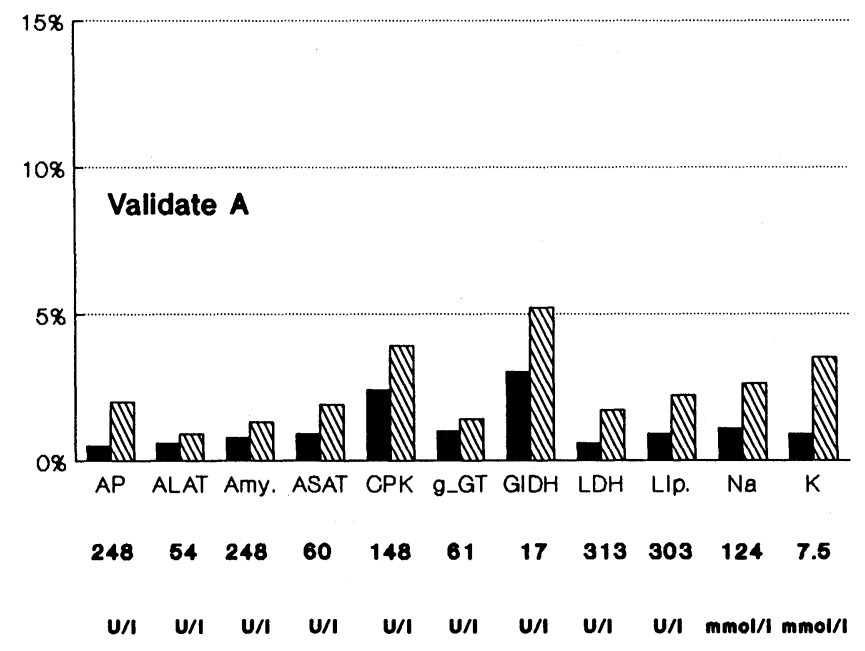

within run $\mathrm{Mll}$ between days betw. days. comp.

Figure 2(a). Imprecision (enzymes and flame photometry): withinrun and between-days on both $A U 5031$ and the respective comparison instruments. The assigned values in the three commercial control sera are given at the bottom of the graphs. 

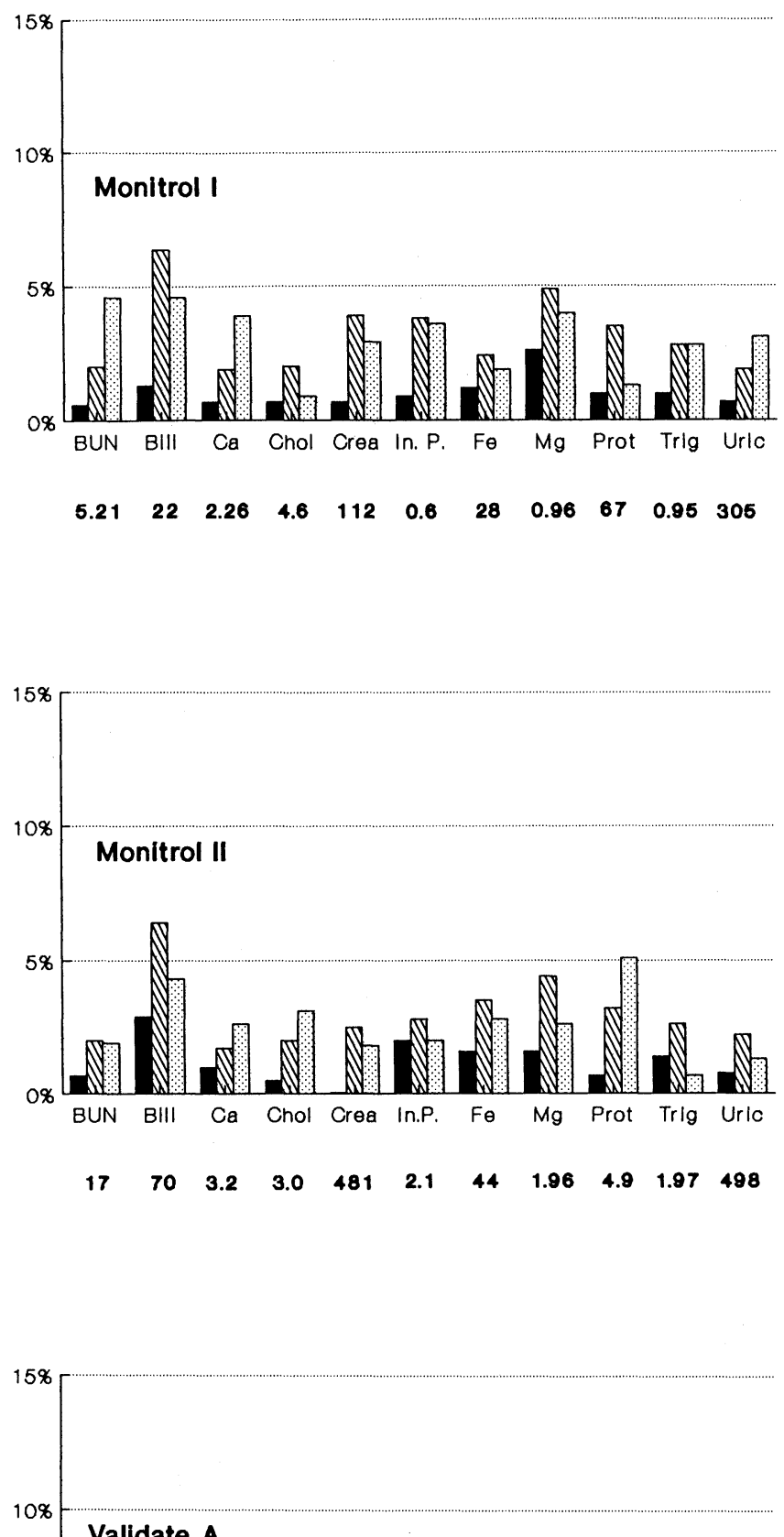

Validate A

$0 \%$

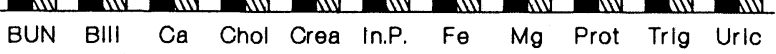

$\begin{array}{lllllllllll}19 & 70 & 3.4 & 2.3 & 265 & 2.6 & 12 & 0.93 & 51 & 0.6 & 440\end{array}$

mmoln umol/ mmol/l mmol/ umol/ mmol/l umol/l mmol/ o/ mmol/ umol/

within run between days

Figure 2(b). Imprecison (substrates): within-run and betweendays on both $A U 5031$ and the respective comparison instruments. The assigned values in the three commercial control sera are given at the bottom of the graphs.

\section{Results}

Linearity of all eight photometers in a unit and temperature behaviour in cuvettes

The extinction readings of a series of para-nitrophenol dilutions were linear, parallel and reproducible for each of the eight photometers (see figure 1, top). The time
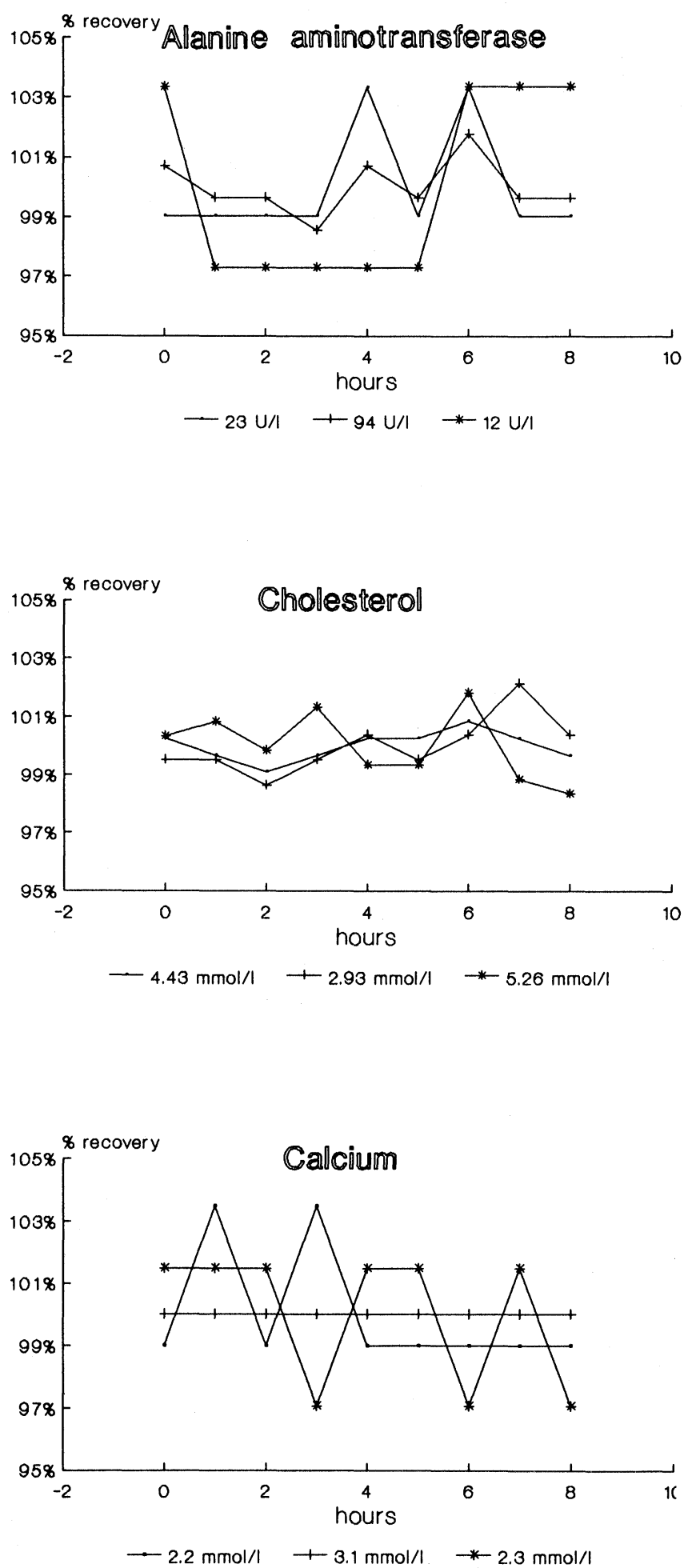

Figure 3. Drift during 8 for three representative parameters. The analyte activities and concentrations, respectively, are given at the bottom of the graphs. 
Table 6. Assigned and found values in three commercial control sera. Between-day imprecision within-run imprecision. Three independent series and median.

\begin{tabular}{|c|c|c|c|c|c|c|c|c|}
\hline \multirow{3}{*}{$\begin{array}{l}\text { Analyte } \\
\text { (Units) }\end{array}$} & \multirow{3}{*}{$\begin{array}{l}\text { Control } \\
\text { material }\end{array}$} & \multirow{3}{*}{$\begin{array}{l}\text { Assigned } \\
\text { values }\end{array}$} & \multirow{3}{*}{$\begin{array}{l}\text { Found } \\
\text { value }\end{array}$} & \multirow{3}{*}{$\begin{array}{l}\text { Between } \\
\text { days }\end{array}$} & \multicolumn{4}{|c|}{ Imprecision } \\
\hline & & & & & \multicolumn{4}{|c|}{ Within-run } \\
\hline & & & & & & ree ser & & Median \\
\hline \multicolumn{9}{|l|}{ 1. Enzymes } \\
\hline Alkaline phosphatase & M-I & 64 & 63 & $4 \cdot 1$ & $1 \cdot 1$ & $0 \cdot 4$ & $0 \cdot 7$ & $0 \cdot 7$ \\
\hline \multirow[t]{2}{*}{$(\mathrm{U} / \mathrm{l})$} & M-II & 276 & 291 & $2 \cdot 3$ & $0 \cdot 7$ & $0 \cdot 7$ & $1 \cdot 1$ & $0 \cdot 7$ \\
\hline & Val-A & 248 & 237 & $2 \cdot 0$ & $0 \cdot 6$ & $0 \cdot 5$ & $0 \cdot 5$ & $0 \cdot 5$ \\
\hline Alanine aminotransferase & M-I & 23 & 17 & $3 \cdot 7$ & $0 \cdot 6$ & $0 \cdot 7$ & $0 \cdot 7$ & $0 \cdot 7$ \\
\hline \multirow[t]{2}{*}{$(\mathrm{U} / \mathrm{l})$} & M-II & 86 & 64 & $1 \cdot 7$ & $0 \cdot 9$ & $1 \cdot 0$ & $1 \cdot 9$ & $1 \cdot 0$ \\
\hline & Val-A & 54 & 44 & $0 \cdot 9$ & $1 \cdot 0$ & $0 \cdot 6$ & $0 \cdot 5$ & $0 \cdot 6$ \\
\hline Amylase & M-I & 64 & 58 & $4 \cdot 8$ & $0 \cdot 7$ & $1 \cdot 3$ & $0 \cdot 8$ & $0 \cdot 8$ \\
\hline \multirow{2}{*}{$(\mathrm{U} / \mathrm{l})$} & M-II & 403 & 412 & $3 \cdot 2$ & $2 \cdot 3$ & $2 \cdot 0$ & $1 \cdot 8$ & $1 \cdot 8$ \\
\hline & Val-A & 248 & 275 & $1 \cdot 3$ & $0 \cdot 8$ & $5 \cdot 3$ & $0 \cdot 7$ & $0 \cdot 8$ \\
\hline \multirow{2}{*}{$\begin{array}{l}\text { Aspartate aminotransferase } \\
(\mathrm{U} / 1)\end{array}$} & M-I & 26 & 21 & $3 \cdot 3$ & $0 \cdot 0$ & $0 \cdot 6$ & $0 \cdot 8$ & $0 \cdot 6$ \\
\hline & M-II & 61 & 52 & $2 \cdot 0$ & $1 \cdot 9$ & $1 \cdot 4$ & $1 \cdot 4$ & $1 \cdot 4$ \\
\hline \multirow{3}{*}{$\begin{array}{l}\text { Creatine phosphokinase } \\
(\mathrm{U} / \mathrm{l})\end{array}$} & $\begin{array}{l}\text { Val-A } \\
\text { M-I }\end{array}$ & $\begin{array}{l}60 \\
39\end{array}$ & $\begin{array}{l}48 \\
45\end{array}$ & $\begin{array}{l}1 \cdot 9 \\
7 \cdot 6\end{array}$ & $\begin{array}{l}1 \cdot 1 \\
1 \cdot 3\end{array}$ & $\begin{array}{l}0 \cdot 9 \\
1 \cdot 5\end{array}$ & $\begin{array}{l}0 \cdot 6 \\
1 \cdot 8\end{array}$ & $\begin{array}{l}0.9 \\
1.5\end{array}$ \\
\hline & $\mathrm{M}-\mathrm{II}$ & 140 & 133 & $7 \cdot 4$ & $2 \cdot 2$ & $1 \cdot 7$ & $2 \cdot 4$ & $2 \cdot 2$ \\
\hline & Val-A & 148 & 136 & $3 \cdot 9$ & $2 \cdot 6$ & $0 \cdot 8$ & $2 \cdot 4$ & $2 \cdot 4$ \\
\hline$\gamma$-glutamyl transferase new & M-I & 14 & 12 & $6 \cdot 5$ & $1 \cdot 3$ & $1 \cdot 5$ & $1 \cdot 6$ & $1 \cdot 5$ \\
\hline \multirow{2}{*}{$(\mathrm{U} / 1)$} & M-II & 59 & 51 & $4 \cdot 4$ & $1 \cdot 5$ & $2 \cdot 5$ & $0 \cdot 0$ & $1 \cdot 5$ \\
\hline & Val-A & 61 & 52 & $1 \cdot 4$ & $3 \cdot 0$ & $0 \cdot 6$ & $1 \cdot 2$ & $1 \cdot 2$ \\
\hline \multirow{3}{*}{$\begin{array}{l}\text { Glutamate dehydrogenase } \\
(\mathrm{U} / \mathrm{l})\end{array}$} & M-I & $4 \cdot 7$ & 4 & $14 \cdot 4$ & $8 \cdot 2$ & $11 \cdot 6$ & $10 \cdot 1$ & $10 \cdot 1$ \\
\hline & M-II & $11 \cdot 5$ & 11 & $8 \cdot 8$ & $4 \cdot 2$ & $7 \cdot 1$ & $5 \cdot 3$ & $5 \cdot 3$ \\
\hline & Val-A & $17 \cdot 3$ & 16 & $5 \cdot 2$ & $4 \cdot 0$ & $8 \cdot 3$ & $4 \cdot 0$ & $4 \cdot 0$ \\
\hline Lactate dehydrogenase & M-I & 181 & 167 & $4 \cdot 1$ & $0 \cdot 4$ & $1 \cdot 5$ & $0 \cdot 4$ & $0 \cdot 4$ \\
\hline$(\mathrm{U} / \mathrm{l})$ & M-II & 393 & 358 & $3 \cdot 2$ & $1 \cdot 0$ & $0 \cdot 6$ & $0 \cdot 3$ & $0 \cdot 6$ \\
\hline & Val-A & 313 & 289 & $1 \cdot 7$ & $0 \cdot 5$ & $0 \cdot 5$ & $0 \cdot 5$ & $0 \cdot 6$ \\
\hline Lipase & M-I & 388 & 396 & $5 \cdot 0$ & $1 \cdot 1$ & 0.9 & $1 \cdot 7$ & $1 \cdot 1$ \\
\hline$(\mathrm{U} / \mathrm{l})$ & M-II & 695 & 702 & $3 \cdot 2$ & $1 \cdot 8$ & $1 \cdot 6$ & $1 \cdot 4$ & $1 \cdot 6$ \\
\hline & Val-A & 303 & 317 & $2 \cdot 2$ & $0 \cdot 9$ & $0 \cdot 9$ & $0 \cdot 8$ & $0 \cdot 9$ \\
\hline 2. Flame photometry & & & & & & & & \\
\hline Sodium & M-I & 139 & 140 & $2 \cdot 3$ & $0 \cdot 4$ & $0 \cdot 0$ & $1 \cdot 0$ & $0 \cdot 4$ \\
\hline$(\mathrm{mmol} / \mathrm{l})$ & M-II & 119 & 117 & $2 \cdot 0$ & $0 \cdot 0$ & $0 \cdot 0$ & $0 \cdot 2$ & $0 \cdot 0$ \\
\hline & Val-A & 124 & 124 & $2 \cdot 6$ & $1 \cdot 1$ & $0 \cdot 5$ & $1 \cdot 2$ & $1 \cdot 1$ \\
\hline Potassium & M-I & $4 \cdot 3$ & $4 \cdot 3$ & $2 \cdot 2$ & $0 \cdot 0$ & $0 \cdot 0$ & $1 \cdot 9$ & $0 \cdot 0$ \\
\hline$(\mathrm{mmol} / \mathrm{l})$ & M-II & $6 \cdot 7$ & $7 \cdot 2$ & $3 \cdot 0$ & $0 \cdot 7$ & $1 \cdot 1$ & $3 \cdot 2$ & $1 \cdot 1$ \\
\hline & Val-A & $7 \cdot 5$ & $6 \cdot 9$ & $3 \cdot 5$ & $0 \cdot 9$ & $0 \cdot 7$ & $2 \cdot 1$ & $0 \cdot 9$ \\
\hline 3. Substrates & & & & & & & & \\
\hline Blood urea nitrogen & M-I & $5 \cdot 2$ & 5 & $2 \cdot 0$ & $0 \cdot 6$ & $1 \cdot 3$ & $0 \cdot 5$ & $0 \cdot 6$ \\
\hline$(\mathrm{mmol} / \mathrm{l})$ & M-II & $17 \cdot 3$ & 18 & $2 \cdot 0$ & $1 \cdot 1$ & $0 \cdot 7$ & $0 \cdot 7$ & $0 \cdot 7$ \\
\hline & Val-A & $18 \cdot 9$ & 17 & $4 \cdot 6$ & $0 \cdot 4$ & $0 \cdot 4$ & 0.5 & $0 \cdot 4$ \\
\hline Bilirubin & M-I & $22 \cdot 1$ & 22 & $6 \cdot 4$ & $1 \cdot 3$ & $0 \cdot 7$ & $2 \cdot 4$ & $1 \cdot 3$ \\
\hline$(\mathrm{umol} / \mathrm{l})$ & $\mathrm{M}-11$ & 70 & 84 & $3 \cdot 2$ & $2 \cdot 9$ & $0 \cdot 0$ & $4 \cdot 6$ & $2 \cdot 9$ \\
\hline Calcium & al-A & 74 & 76 & $4 \cdot 0$ & $1 \cdot 9$ & $1 \cdot 4$ & $0 \cdot 0$ & $1 \cdot 4$ \\
\hline $\begin{array}{l}\text { Cialcium } \\
(\mathrm{mmol} / \mathrm{l})\end{array}$ & $\begin{array}{l}M-1 \\
M-I I\end{array}$ & $2 \cdot 3$ & $2 \cdot 2$ & $\begin{array}{l}1.9 \\
1.7\end{array}$ & $0 \cdot 1$ & $\begin{array}{l}0.7 \\
2.2\end{array}$ & $1 \cdot 3$ & $0 \cdot 7$ \\
\hline & M-11 & $3 \cdot 2$ & $3 \cdot 2$ & $1 \cdot \%$ & $0 \cdot 0$ & $2 \cdot 2$ & $1 \cdot 0$ & $1 \cdot 0$ \\
\hline Cholesterol & al-A & $3 \cdot 4$ & $3 \cdot 0$ & $2 \cdot 2$ & $1 \cdot 6$ & $0 \cdot 9$ & $0 \cdot 7$ & 0.9 \\
\hline $\begin{array}{l}\text { Ciholesterol } \\
(\mathrm{mmol} / \mathrm{l})\end{array}$ & M-I & $4 \cdot 6$ & $4 \cdot 4$ & $2 \cdot 0$ & $0 \cdot 4$ & 0.7 & $0 \cdot 7$ & $0 \cdot 7$ \\
\hline & M-II & $3 \cdot 0$ & $2 \cdot 8$ & $2 \cdot 0$ & $0 \cdot 6$ & $0 \cdot 5$ & 0.5 & $0 \cdot 5$ \\
\hline & Val-A & $2 \cdot 3$ & $2 \cdot 4$ & $2 \cdot 0$ & $0 \cdot 9$ & $0 \cdot 6$ & $0 \cdot 4$ & $0 \cdot 6$ \\
\hline $\begin{array}{l}\text { Creatinine } \\
\text { (umol/l) }\end{array}$ & M-I & 112 & 113 & $3 \cdot 9$ & $0 \cdot 7$ & $0 \cdot 8$ & $0 \cdot 7$ & $0 \cdot 7$ \\
\hline & M-II & 481 & 511 & $2 \cdot 5$ & $0 \cdot 0$ & $0 \cdot 0$ & $2 \cdot 3$ & $0 \cdot 0$ \\
\hline & Val-A & 265 & 307 & $2 \cdot 4$ & $1 \cdot 3$ & $1 \cdot 2$ & $0 \cdot 0$ & $1 \cdot 2$ \\
\hline Phosphate & M-I & $0 \cdot 9$ & $0 \cdot 8$ & $3 \cdot 8$ & $1 \cdot 2$ & $0 \cdot 8$ & $0 \cdot 9$ & $0 \cdot 9$ \\
\hline$(\mathrm{mmol} / \mathrm{l})$ & M-II & $2 \cdot 1$ & 1.9 & $2 \cdot 8$ & 2.0 & $1 \cdot 6$ & $1 \cdot 8$ & $1 \cdot 8$ \\
\hline & Val-A & $2 \cdot 6$ & $2 \cdot 4$ & $2 \cdot 5$ & $0 \cdot 8$ & $0 \cdot 9$ & $0 \cdot 9$ & $0 \cdot 9$ \\
\hline Iron & M-I & 29 & $28 \cdot 0$ & $2 \cdot 4$ & $1 \cdot 2$ & $1 \cdot 2$ & $1 \cdot 8$ & $1 \cdot 2$ \\
\hline (umol/I) & M-II & 44 & $42 \cdot 0$ & $3 \cdot 5$ & $1 \cdot 8$ & $1 \cdot 6$ & $1 \cdot 1$ & $1 \cdot 6$ \\
\hline & Val-A & 13 & $12 \cdot 5$ & $2 \cdot 5$ & $2 \cdot 6$ & $2 \cdot 7$ & $1 \cdot 0$ & $2 \cdot 6$ \\
\hline
\end{tabular}




\begin{tabular}{|c|c|c|c|c|c|c|c|c|}
\hline \multirow{3}{*}{$\begin{array}{l}\text { Analyte } \\
\text { (Units) }\end{array}$} & \multirow{3}{*}{$\begin{array}{l}\text { Control } \\
\text { material }\end{array}$} & \multirow{3}{*}{$\begin{array}{l}\text { Assigned } \\
\text { values }\end{array}$} & \multirow{3}{*}{$\begin{array}{l}\text { Found } \\
\text { value }\end{array}$} & \multirow{3}{*}{$\begin{array}{l}\text { Between } \\
\text { days }\end{array}$} & \multicolumn{4}{|c|}{ Imprecision } \\
\hline & & & & & \multicolumn{4}{|c|}{ Within-run } \\
\hline & & & & & \multicolumn{3}{|c|}{ (Three series) } & Median \\
\hline Magnesium & M-I & 0.95 & $1 \cdot 0$ & $4 \cdot 9$ & $0 \cdot 8$ & $5 \cdot 1$ & $1 \cdot 4$ & $1 \cdot 4$ \\
\hline$(\mathrm{mmol} / \mathrm{l})$ & M-II & 1.96 & $1 \cdot 6$ & $4 \cdot 4$ & $1 \cdot 6$ & $3 \cdot 6$ & $1 \cdot 0$ & $1 \cdot 6$ \\
\hline & Val-A & 0.93 & $1 \cdot 8$ & $3 \cdot 7$ & 0.9 & $2 \cdot 6$ & $0 \cdot 9$ & 0.9 \\
\hline Total protein & M-I & 67 & 64 & $3 \cdot 5$ & $1 \cdot 0$ & $1 \cdot 2$ & $0 \cdot 8$ & $1 \cdot 0$ \\
\hline$(\mathrm{mmol} / \mathrm{l})$ & M-II & 48 & 44 & $3 \cdot 2$ & 0.7 & $0 \cdot 0$ & $1 \cdot 1$ & $0 \cdot 7$ \\
\hline & Val-A & 51 & 44 & $3 \cdot 4$ & $0 \cdot 0$ & $0 \cdot 5$ & $0 \cdot 9$ & $0 \cdot 5$ \\
\hline Triglycerides & M-I & $0 \cdot 96$ & 0.9 & $2 \cdot 8$ & $1 \cdot 0$ & $0 \cdot 6$ & $1 \cdot 6$ & $1 \cdot 0$ \\
\hline$(\mathrm{mmol} / \mathrm{l})$ & M-II & 1.97 & $2 \cdot 1$ & $2 \cdot 6$ & $1 \cdot 4$ & $1 \cdot 0$ & $1 \cdot 7$ & $1 \cdot 4$ \\
\hline & Val-A & $0 \cdot 6$ & $0 \cdot 8$ & $3 \cdot 3$ & $1 \cdot 0$ & $1 \cdot 1$ & $0 \cdot 9$ & $1 \cdot 0$ \\
\hline Uric acid & M-I & 305 & 299 & 1.9 & $0 \cdot 7$ & $0 \cdot 5$ & $0 \cdot 9$ & $0 \cdot 7$ \\
\hline (umol/l) & M-II & 498 & 534 & $2 \cdot 2$ & $0 \cdot 8$ & $1 \cdot 1$ & $0 \cdot 4$ & $0 \cdot 8$ \\
\hline
\end{tabular}

Table 7. Linearity of the enzyme and substrate tests.

\begin{tabular}{|c|c|c|c|c|}
\hline & Unit & $\begin{array}{l}\text { Measured } \\
\text { up to }\end{array}$ & $\begin{array}{l}\text { Found } \\
\text { linear } \\
\text { up to }\end{array}$ & $\begin{array}{l}\text { Upper limit of } \\
\text { linearity } \\
\text { (declaration of } \\
\text { manufacturer) }\end{array}$ \\
\hline \multicolumn{5}{|l|}{ Enzymes } \\
\hline Alkaline phosphatase & $\mathrm{U} / 1$ & 5200 & 5200 & 1800 \\
\hline Alanine aminotransferase & $\mathrm{U} / \mathrm{l}$ & 1930 & 1930 & 400 \\
\hline Amylase & $\mathrm{U} / \mathrm{l}$ & 558 & 558 & 430 \\
\hline Aspartate aminotransferase & $\mathrm{U} / \mathrm{l}$ & 880 & 880 & 400 \\
\hline Creatine kinase & $\mathrm{U} / 1$ & 800 & 800 & 1100 \\
\hline$\gamma$-glutamyltransferase & $\mathrm{U} / 1$ & 2100 & 1790 & 1600 \\
\hline Glutamate lact. dehydrogeanse & $\mathrm{U} / \mathrm{l}$ & 320 & 150 & 38 \\
\hline Lactate dehydrogenase & $\mathrm{U} / 1$ & 670 & 670 & 650 \\
\hline Lipase & $\mathrm{U} / \mathrm{l}$ & 1200 & 650 & $700\left(25^{\circ} \mathrm{C}\right)$ \\
\hline \multicolumn{5}{|l|}{ Substrates } \\
\hline Blood urea nitrogen & $\mathrm{mmol} / \mathrm{l}$ & 44 & 44 & 33 \\
\hline Bilirubin & $\mu \mathrm{mol} / \mathrm{l}$ & 430 & 430 & 390 \\
\hline Calcium & $\mathrm{mmol} / \mathrm{l}$ & $6 \cdot 5$ & $6 \cdot 5$ & $5 \cdot 1$ \\
\hline Cholesterol & $\mathrm{mmol} / \mathrm{l}$ & $17 \cdot 2$ & $17 \cdot 2$ & $15 \cdot 5$ \\
\hline Greatinine & $\mu \mathrm{mol} / 1$ & 2840 & 2840 & 2650 \\
\hline Inorganic phosphate & $\mathrm{mmol} / \mathrm{l}$ & 6.9 & 6.9 & $6 \cdot 5$ \\
\hline Iron & $\mu \mathrm{mol} / 1$ & 215 & 215 & 180 \\
\hline Magnesium & $\mathrm{mmol} / \mathrm{l}$ & $2 \cdot 0$ & $2 \cdot 0$ & $2 \cdot 0$ \\
\hline Total protein & $\mathrm{g} / \mathrm{l}$ & 150 & 150 & 110 \\
\hline Triglycerides & $\mathrm{mmol} / \mathrm{l}$ & $15 \cdot 9$ & $15 \cdot 9$ & $6 \cdot 8$ \\
\hline Uric acid & $\mu \mathrm{mol} / 1$ & 1770 & 1770 & 1190 \\
\hline
\end{tabular}

course of temperature lowering caused by the addition of cooled reagent 1 showed that the reaction temperature of $37^{\circ} \mathrm{C}$ had been reached in the cuvette before reading by photometer 1 and additon of reagent 2 (168 and $204 \mathrm{~s}$ later, respectively). This is illustrated in figure 1.

\section{Imprecision}

The within-run imprecision and the between-day imprecision are shown in figure 2(a) (enzymes) and figure 2(b) (substrates). For two of the control sera the imprecision values are also given for the comparison instruments. The values presented in the figures are medians from three independent measurement series. Exact figures are listed in table 6 .

It is apparent from this data that 15 of the 22 evaluated tests gave a within-run imprecision of below $1 \cdot 5 \%$. Six of the seven remaining tests gave values below $2 \cdot 9 \%$ - only glutamate dehydrogenase gave a high imprecision which, however, is not due to a failure of the test or of the analyser, but is a consequence of the low activities which are measured by this test. This performance can be rated as very good.

The between-day imprecision was below $4.5 \%$ for at least two out of three control sera. Exceptions were creatine 


\section{Specimen carry-over \\ Alkaline phosphatase}

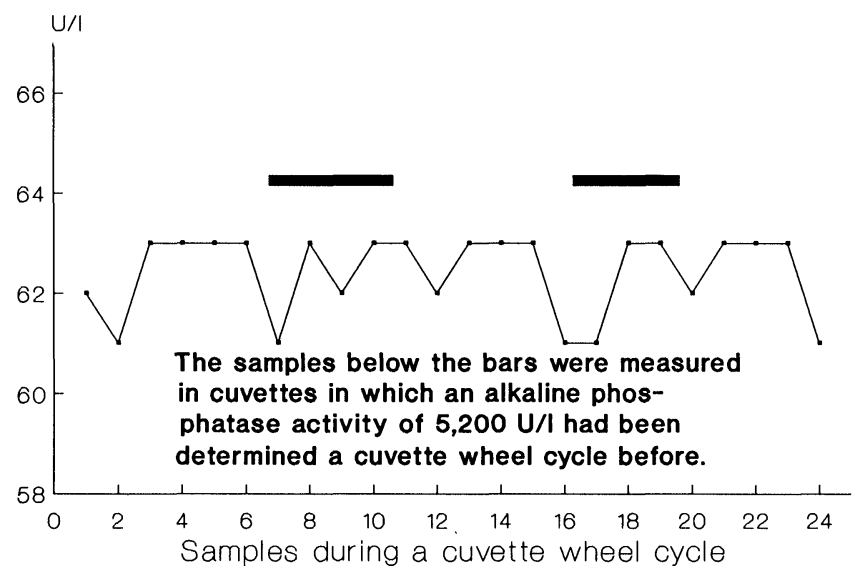

Figure 4. Specimen-related carry-over: alkaline phosphatase measurements of 24 samples (one cycle of the cuvette wheel) of a serum pool with low analyte activity. Samples with an activity of alkaline phosphatase of $5200 \mathrm{U} / \mathrm{l}$ had been measured in cuvettes 6 to 10 and 16 to 20, respectively, during the preceeding wheel cycle.

kinase $(7 \cdot 6,7 \cdot 2$ and $2.9 \%)$ and, again, glutamate dehydrogenase.

The between-day imprecisions of the comparison instrument are also shown in figure 2 (for Monitrol I and II only) - the AU 5031 matches this performance.

Close imprecisions were reported by other evaluators who found values surpassing the comparison instrument [3].

\section{Drift}

The results of investigations on drift over $8 \mathrm{~h}$ were inspected visually after blotting the percentage deviations from the starting value (100\%) over a time scale. Figure 3 displays three representative plots. A continuous trend either increasing or decreasing could not be detected for any of the 22 parameters. Deviations were below $5 \%$ for all tests. This result is in contrast to Rohac et al. who reported drifts for cholesterol, triglycerides and uric acid, but did not discuss this finding further [3]. Hodgin et al. omitted this aspect from their evaluation [2].

\section{Linearities}

Both the linearities found, and the linearity ranges declared by the manufacturer, are given in table 7 . The linearities found were better than the manufacturer's for all tests with the exceptions of creatinine kinase and lipase. In fact, a limited linearity was found only for gamma-GT, glutamate dehydrogenase and lipase. For the remaining tests the limitation of linearity is beyond the highest value measured. The findings are in good agreement with the results of other evaluators [2 and 3].

\section{Specimen-related carry-over}

A potential carry-over of sample residue due to an insufficient washing of the cuvettes was investigated by measuring alkaline phosphatase in cuvettes which had been used before for the determination of the same analyte in a very high activity $(5200 \mathrm{U} / \mathrm{l})$. The results were compared with those which were obtained from the same sample in cuvettes, which, a cuvette wheel before, had been used for the determination of this analyte in a low activity $(62 \mathrm{U} / \mathrm{l})$. The results are displayed in figure 4 which shows the measured values of this sample in 24 cuvettes (one cycle of the cuvette wheel). It is apparent from the figure that no difference could be detected. The Wilcoxon test did not show a significance difference between both sets of values $(p=0 \cdot 84)$. Thus, the specimen carry-over was smaller than $0.04 \%$. Carry-over effects between $0 \cdot 1 \%$ and $5.33 \%$ were reported for different parameters by other evaluators [1 and 2]. However, neither investigator took into consideration the sequence of cuvettes which were assigned to the respective tests.

\section{Specimen-independent carry-over}

A carry-over caused by transfer of reagent due to an insufficient washing of the mixer blades was tested in two reagent lines which were served by the same mixer blade (reagent line 1 and reagent line 5). The triglycerides values (means of quadruplicate measurement in reagent line 5) in 10 serum samples did not differ in the Wilcoxon test $(p=0 \cdot 76)$, regardless of whether concomitant lipase determination had been carried out in reagent line 2 or not. Rohac et al. carried out a similar experiment and found a considerable carry-over leading to threefold lipase measurements in combination with triglycerides. Their results, however, are difficult to discuss because of a lack of experimental detail [3].

\section{Assessment of accuracy}

Recovery of assigned values in quality-control sera

The recovered values of all analytes in 10 commercial control sera were expressed as percentage of the assigned values. The medians and the 10th and 90 th percentiles of the respective values are displayed in figure 5 . Fourteen of 22 tests yielded recoveries within the $5 \%$ range. Five tests were in the range between $5 \%$ and $10 \%$ ( $\gamma$-glutamyl transferase, lactate dehydrogenase, bilirubin, phosphate and total protein) and three tests were in the range between 10 and $18 \%$ (alanine aminotrans-ferase, aspartate aminotransferase and creatinine).

\section{Comparison with other analytical routine procedures}

The results obtained by determination of all parameters in 100 routine sera on the Olympus AU 5031 and on routine instruments (see tables 3 and 4) were correlated using the method of Bablock and Passing [4]. The results of this statistical evaluation are given in table 8 and figure 6 .

The correlations were close for all tests. A correction was unnecessary for eight out of 22 tests $(\gamma$-glutamyl transferase, sodium, blood urea nitrogen, cholesterol, creatinine, 


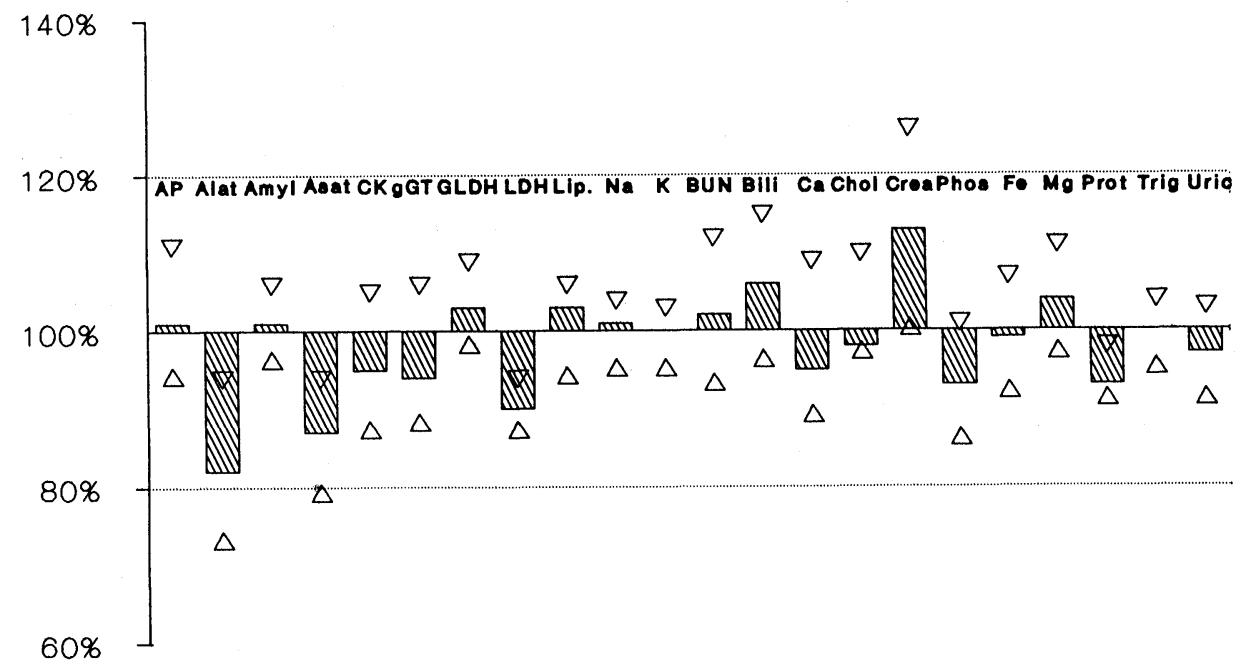

Figure 5. Recovery of assigned values in 12 commercial control sera. The columns represent medians and percentiles (10th, 90th) of the percentage deviations from the assigned values.

iron, triglycerides). The remaining 14 tests differed either in slope (bilirubin, potassium), or in intercept (alanine aminotransferase, creatinine phosphokinase, glutamate dehydrogenase, lipase, inorganic phosphate, uric acid and calcium), or both (alkaline phosphatase, amylase, aspartate aminotransferase, magnesium and total protein). Statistical data are given in table 8 , which displays slope, intercept and the correlation coefficient after regression analysis according to the equation: $y=\mathrm{a} * x+$ b where $y=$ the AU 5031 and $x=$ the comparison instrument. The reasons for the discrepancies were various: different physiochemical methods on the comparison instruments (see tables 3 and 4), different analysis temperatures (see the section on Reagents and comparison instruments) and a lack of accuracy for some methods on the AU 5031 (see figure 5). However, it is unlikely that these discrepancies can be attributed to the performance of the analyser but arise because of the methodological discrepancies summarized above.

The results of these comparisons were discussed with the manufacturers of the respective tests. In consequence, factors of alkaline phosphatase and lactate dehydrogenase have been corrected in accordance with data from the laboratories evaluating the AU analyses.

\section{Assessment of practicability}

Despite the size and capacity of the analyser, the Olympus AU 5031. is easy to run. It is easily accessible from all sides and all mechanical movements can be seen. The data-processing software is sophisticated but can be mastered by a technician after a training period of a few days. The software contains an extensive diagnostic program, which allows a specific detection of technical or electronic problems. Together with a complete system of
LED controls of all mechanical movements problems can rapidly be tracked to their origin thus allowing immediate remedy or better communication with the Olympus service.

The preanalytical preparation of the analyser consists of four steps, which require the time periods given in parentheses: warming up to $37^{\circ} \mathrm{C}$ (60 min); washing of cuvettes and filling of reagent lines with reagent (20 $\mathrm{min})$; reagent blanking plus running controls (20 min). In order to circumvent the long warm-up phase the authors use an electronic clock which starts the warming-up automatically before routine work begins. Thus, the preanalytical phase is reduced to $40 \mathrm{~min}$ and this time is required for such routine activities as checking and replacing the reagents.

During the evaluation period and the subsequent routine work no total shut down of the analyser occurred. However, during the routine period a single unit broke down twice: in both cases the reason was a faulty adjustment of the sensors which control the movement of the washing units. After correction in all three units this problem did not occur again. The most practical and most rapid solution for this emergency was to concentrate 'vital' tests on the remaining units. It was easier to transfer reagents and programs from the faulty unit to the other units, than to exchange the total unit as mentioned above ('Description of the AU 5031 analyser'). This transfer of tests was completed in less than $30 \mathrm{~min}$, including washing of the reagent lines. The units were repaired by the Olympus service technicians before the next morning. No other breakdown causing a severe delay occurred thereafter.

Two modes of sample identification are possible: via terminal or via bar-code identification. The manual prescribes a correct positioning of the bar code onto the sample cup; the vertical slant should be lower than $5^{\circ}$. 

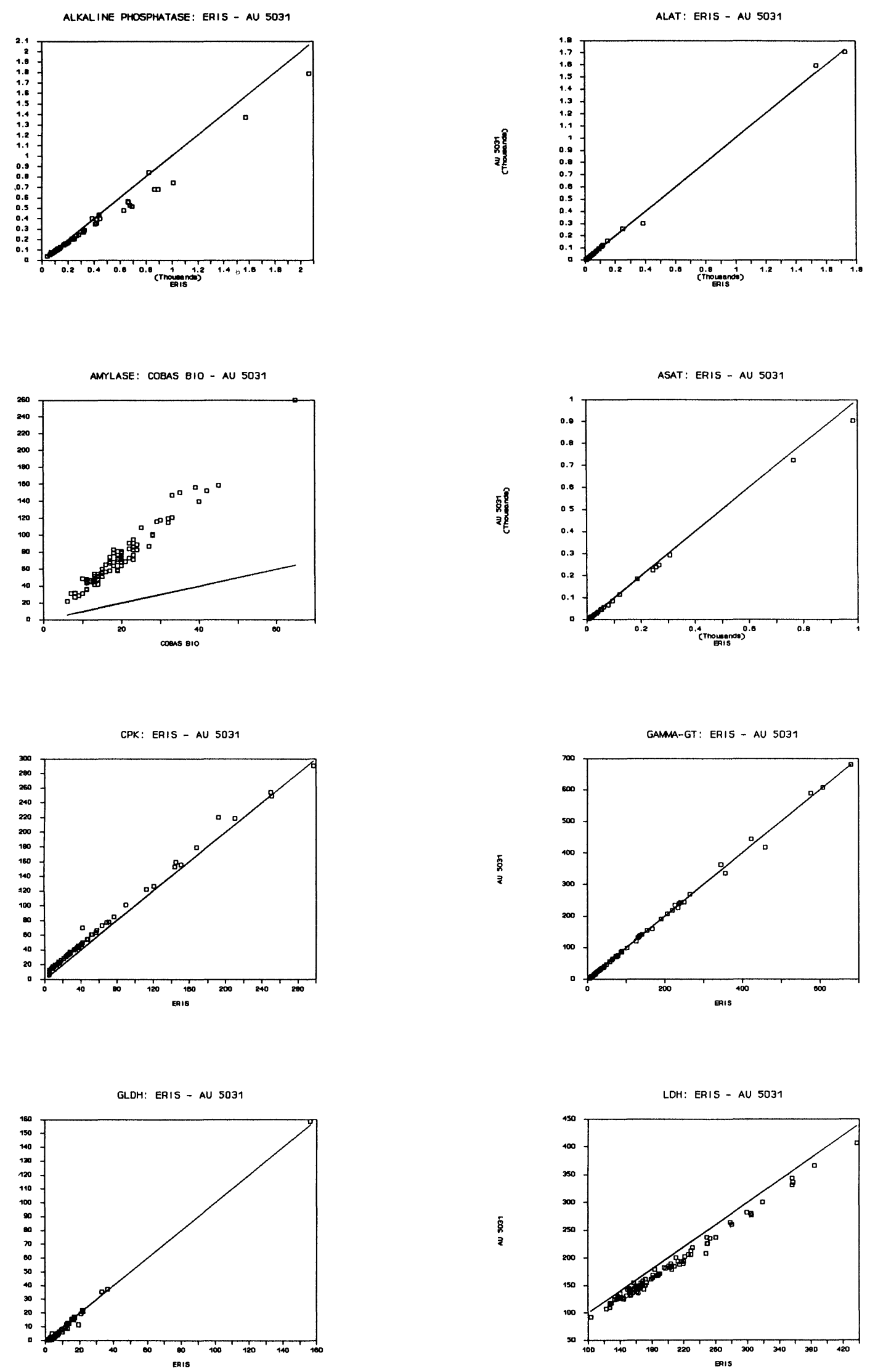

Figure 6(a). Graphical plots of instrument comparison. Statistical data are listed in table 8. 

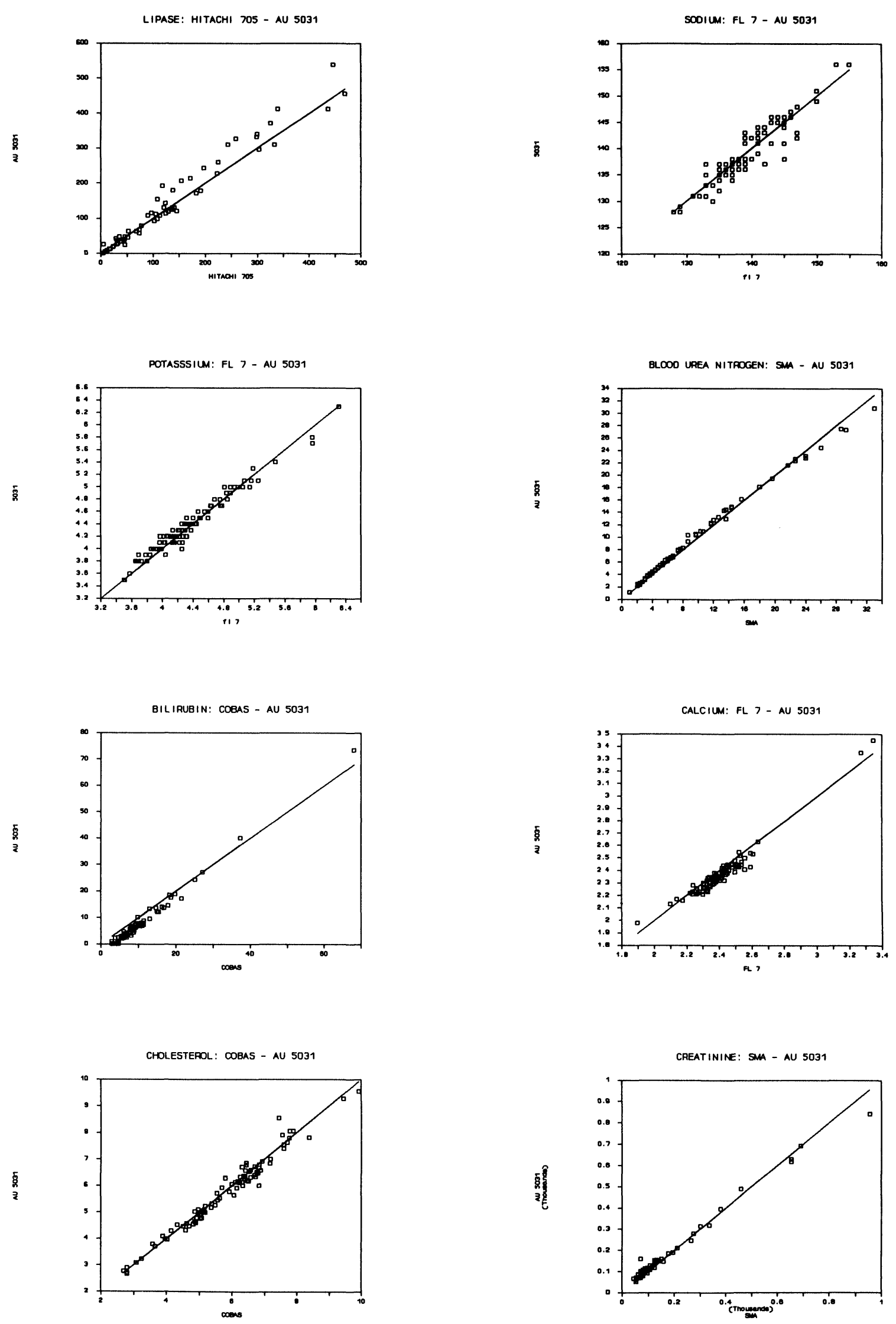

Figure 6(b). Graphical plots of instrument comparison. Statistical data are listed in table 8. 
However, angles up to $15^{\circ}$ are read correctly. In addition, the vertical position may vary up to $10 \mathrm{~mm}$.

The following points would improve the performance of the analyser.

(1) Changing from bar-code reading to sample identification via the terminal required a complete termination of bar-code analyses. This causes inevitable delays of $20 \mathrm{~min}$ for each change.

(2) The software which produces the print-out is inflexible. For example, all available tests and references ranges are printed, even if only one test has been required for a given sample. In addition, flagging of pathologic values ('high' or 'low') cannot be defined differently for both sexes. As a result, this flag is set only according to one reference range, either female or male. Finally, the matrix printer which is delivered
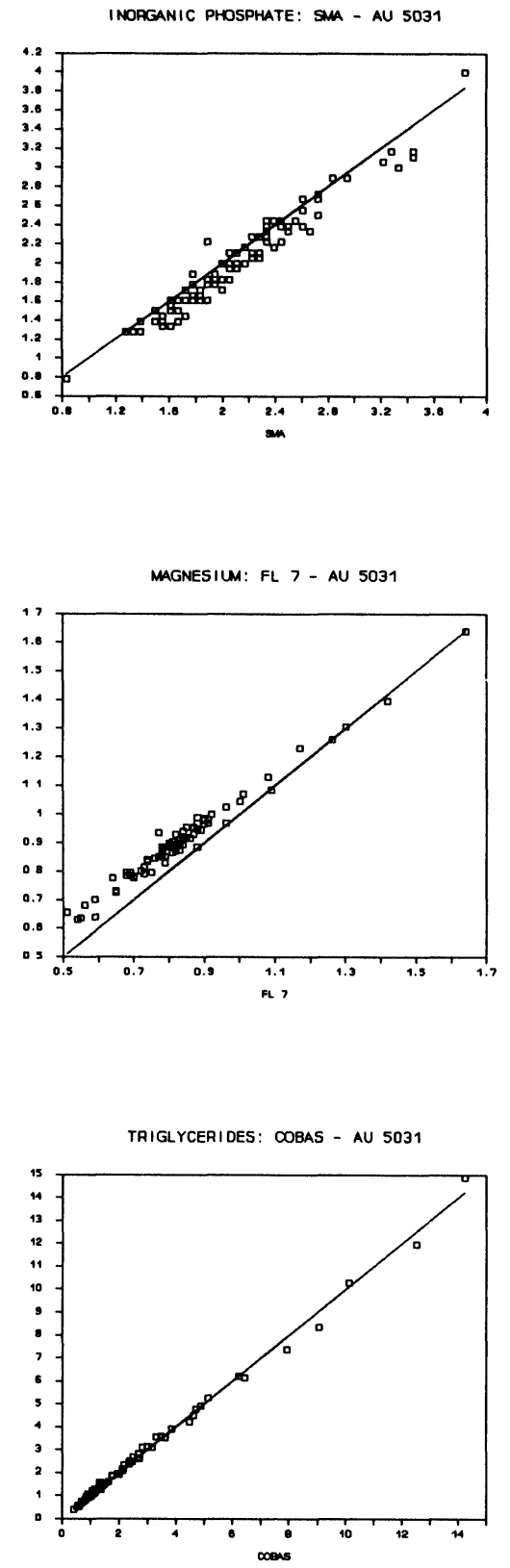

with the analyser is slow and noisy. The authors have connected a personal computer which runs a versatile custom-made report software and serves a quiet, and very rapid, ink-jet printer (the Epson SQ 2500).

(3) The tubing system by which the serum sample is transported to the flame photometer consists of three parts: two narrow tubes made of stainless steel and silicone tubing. Frequent blocks in this system were encountered, which were caused by tiny clots which either pre-existed in the sample or resulted from delayed clotting which could have been triggered by contact with the materials described above. Since an obstruction in the tubing system can result in time losses of up to $45 \mathrm{~min}$ this system should be replaced by a continuous Teflon tubing.

These suggestions have been put to Olympus and it appears that all three are being tested.
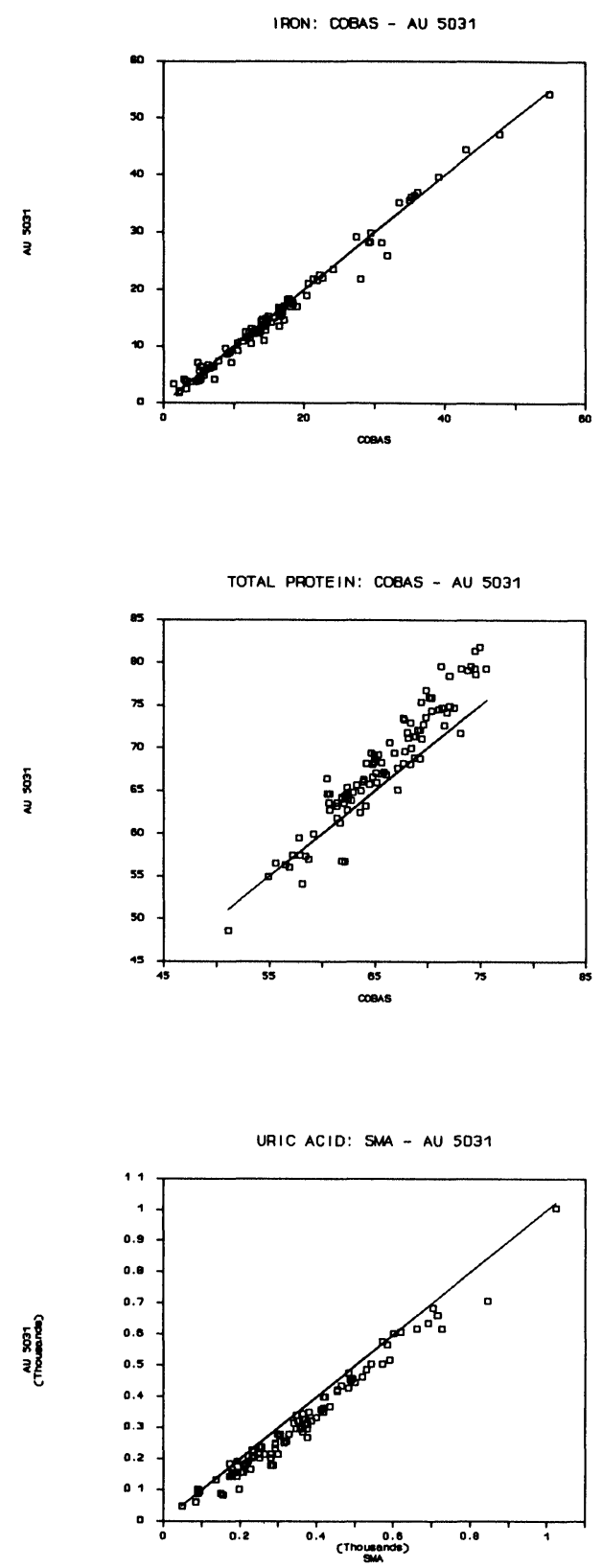

Figure $6(c)$. Graphical plots of instrument comparison. Statistical data are listed in table 8. 
Table 8. Comparison with routine instruments.

\begin{tabular}{|c|c|c|c|c|c|}
\hline \multirow[t]{2}{*}{ Method } & \multicolumn{5}{|c|}{$\begin{array}{l}\text { Regression analysis }\left(y=\mathrm{a}^{*} x+\mathrm{b}\right) \\
y=\mathrm{AU} 5031 ; x=\text { comparison instrument } \\
\mathrm{SE}=\text { standard error of the slope } \\
\mathrm{CC}=\text { correlation coefficient }\end{array}$} \\
\hline & $N$ & $\mathrm{a}$ & $\mathrm{SE}$ & $\mathrm{b}$ & CC \\
\hline \multicolumn{6}{|l|}{ 1. Enzymes } \\
\hline Alkaline phosphatase & 100 & $0 \cdot 845$ & $0 \cdot 013$ & $5 \cdot 5$ & 0.994 \\
\hline Alanine aminotransferase & 100 & $1 \cdot 051$ & $0 \cdot 004$ & $-2 \cdot 6$ & 0.999 \\
\hline Amylase & 100 & 3.925 & $0 \cdot 005$ & $-4 \cdot 0$ & $0 \cdot 980$ \\
\hline Aspartate aminotransferase & 100 & 0.932 & $0 \cdot 002$ & $-1 \cdot 5$ & 0.999 \\
\hline Creatin kinase & 100 & $1 \cdot 000$ & $0 \cdot 005$ & $8 \cdot 0$ & 0.999 \\
\hline$\gamma$-glutamyltransferase & 100 & $1 \cdot 000$ & $0 \cdot 004$ & $-1 \cdot 0$ & $0 \cdot 999$ \\
\hline Glutamate lact. dehydrogenase & 100 & $1 \cdot 012$ & $0 \cdot 008$ & $-1 \cdot 2$ & $0 \cdot 998$ \\
\hline Lactate dehydrogenase & 100 & 0.972 & $0 \cdot 010$ & $-7 \cdot 1$ & $0 \cdot 996$ \\
\hline Lipase & 100 & $1 \cdot 062$ & $0 \cdot 011$ & $6 \cdot 6$ & $0 \cdot 982$ \\
\hline \multicolumn{6}{|l|}{ 2. Flame photometry } \\
\hline Sodium & 100 & $1 \cdot 002$ & $0 \cdot 032$ & $0 \cdot 7$ & $0 \cdot 948$ \\
\hline Potassium & 100 & $0 \cdot 993$ & $0 \cdot 017$ & $0 \cdot 1$ & $0 \cdot 986$ \\
\hline \multicolumn{6}{|l|}{ 3. Substrates } \\
\hline Blood urea nitrogen & 100 & $1 \cdot 00$ & 0.007 & $0 \cdot 3$ & 0.998 \\
\hline Bilirubin & 100 & $1 \cdot 17$ & 0.009 & $3 \cdot 4$ & 0.994 \\
\hline Calcium & 100 & 0.99 & $0 \cdot 040$ & $-0 \cdot 1$ & 0.942 \\
\hline Cholesterol & 100 & 0.98 & $0 \cdot 019$ & $0 \cdot 0$ & 0.985 \\
\hline Creatinine & 100 & 0.97 & $0 \cdot 013$ & 18 & 0.994 \\
\hline Inorganic phosphate & 100 & $1 \cdot 00$ & $0 \cdot 023$ & $-0 \cdot 1$ & 0.976 \\
\hline Iron & 100 & $1 \cdot 00$ & $0 \cdot 013$ & $0 \cdot 8$ & 0.984 \\
\hline Magnesium & 100 & 0.97 & $0 \cdot 012$ & $0 \cdot 2$ & 0.989 \\
\hline Total protein & 100 & $1 \cdot 24$ & $0 \cdot 024$ & -19 & 0.951 \\
\hline Triglycerides & 100 & $1 \cdot 02$ & $0 \cdot 007$ & $0 \cdot 0$ & 0.998 \\
\hline Uric acid & 100 & $0 \cdot 97$ & $0 \cdot 017$ & -24 & 0.988 \\
\hline
\end{tabular}

\section{Conclusion}

The Olympus AU 5031 is a powerful analyser which can be tailored according to the needs of medium and large laboratories. During the evaluation and the subsequent routine period the analyser proved to be very reliable. Both the photometer linearity in a unit and rapid temperature equilibration upon addition of cooled reagent were found satisfactory. Imprecision values very good, while the accuracy of some tests required corrections. Correlations with other routine analysers was close. Neither drift nor a carry-over were detected. Finally, due to the wide ranges of most tests, only a few samples needed to be re-run.

\section{References}

1. Haegkel, R., Busch, E. W., Jennings, R. D., Koкholm, G. and Trughaud, A., ECCLS Document, Vol. 3, No. 2 (1986).

2. Hodgin, P. B. Jr., Moore, W. F. III and Kincaid, H. L., Journal of Automatic Chemistry, 10 (2) (1988), 79.

3. Rohac, M., Hotschek, H., Hajdusich, P., Bayer, P. M., Fischer, G. and GABL, F., Österreichische Krankenhauszeitung, 29 (1988), 315.

4. Passing, H. and Bablock, W. J., Clinical Chemistry and Clinical Biochemistry, 22 (1984), 431. 


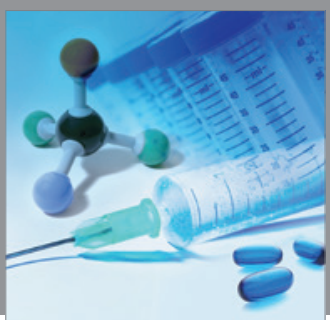

International Journal of

Medicinal Chemistry

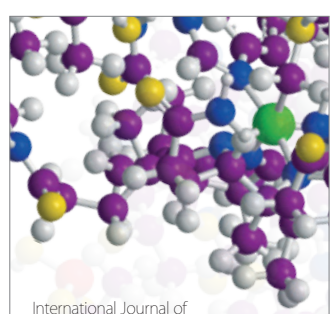

Carbohydrate Chemistry

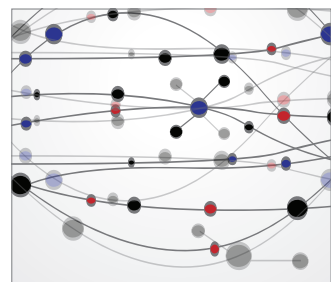

The Scientific World Journal
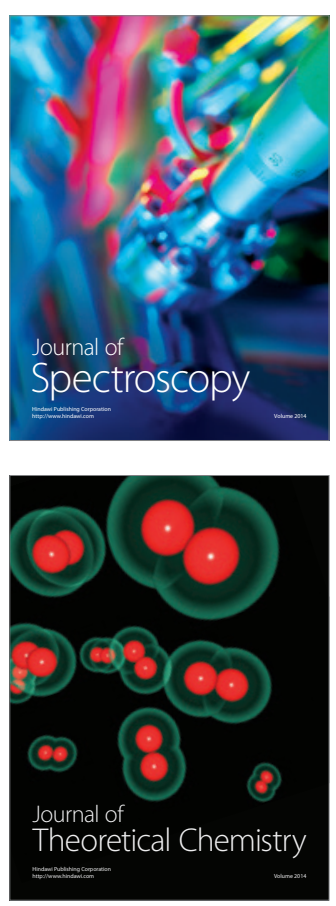
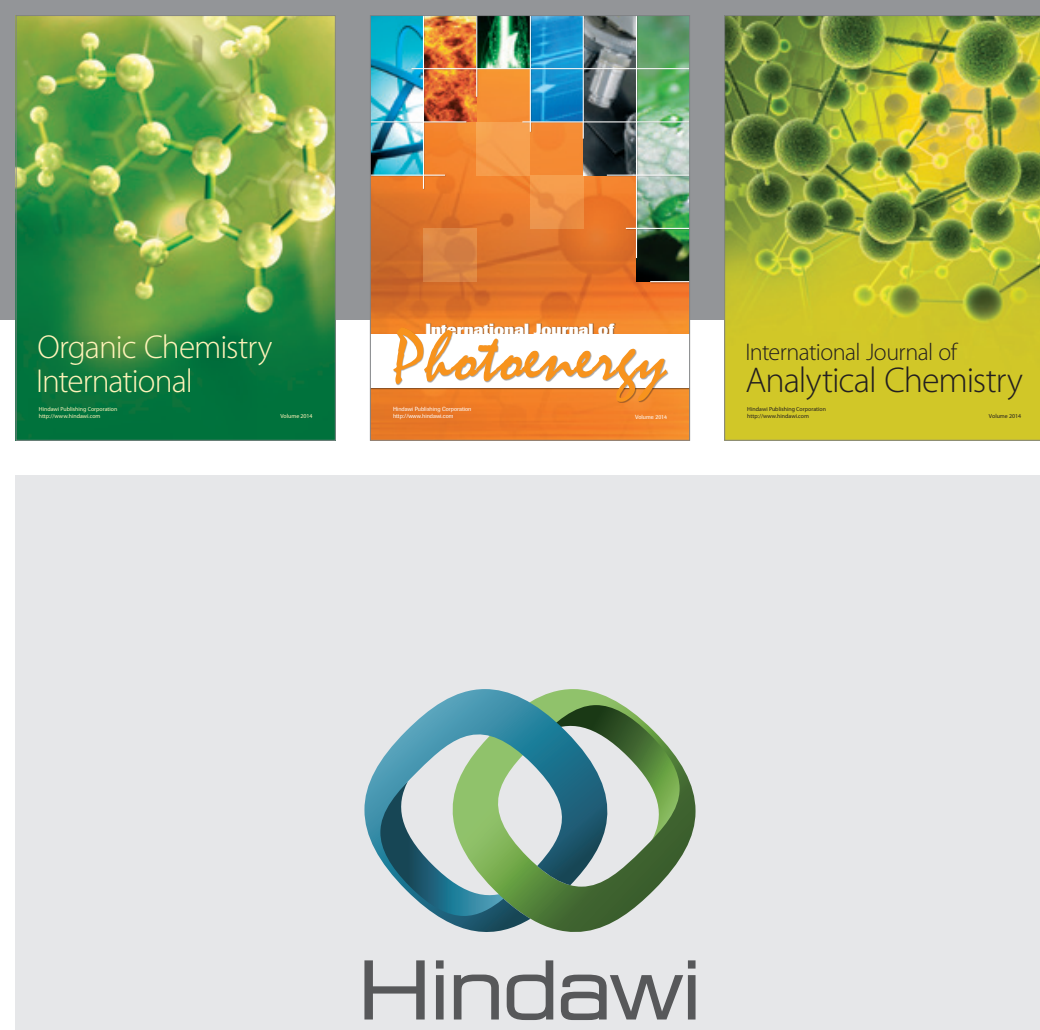

Submit your manuscripts at

http://www.hindawi.com
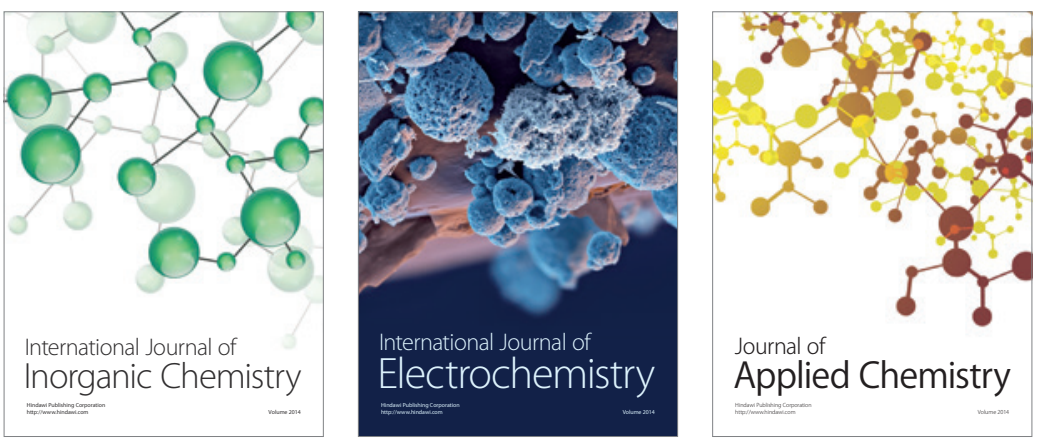

Journal of

Applied Chemistry
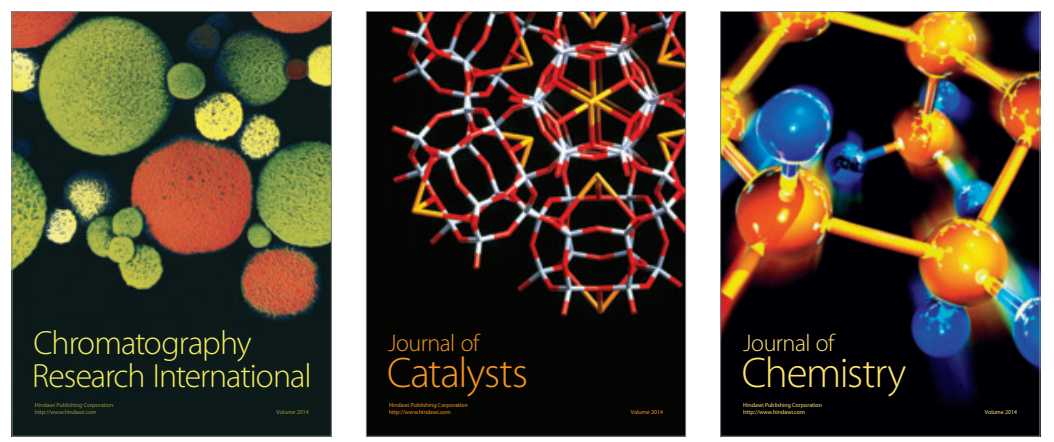
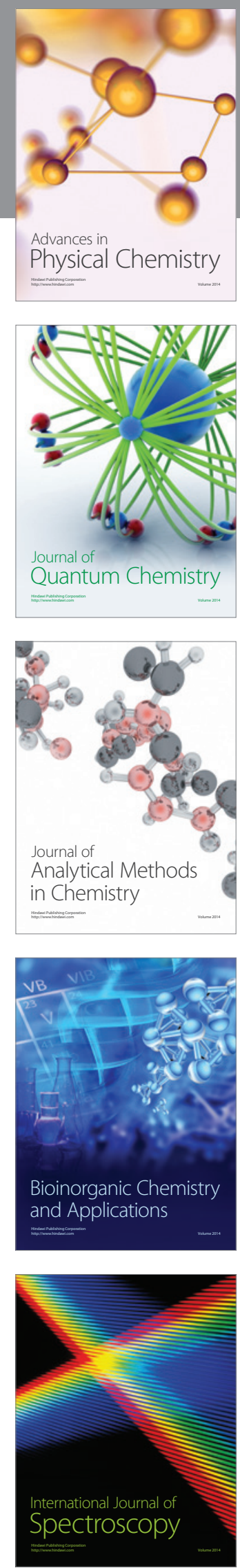